ارزيابى ويزگى هاى رشد و عملكرد هيبريدهاى دو منظوره ذرت در دو سطح كود آبيارى اوره

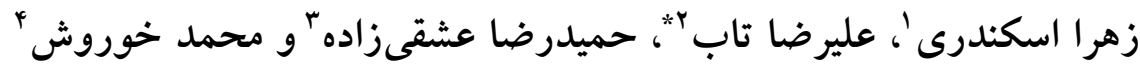

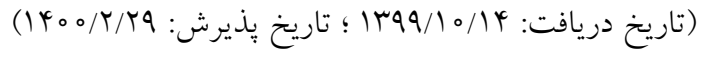

جكيده

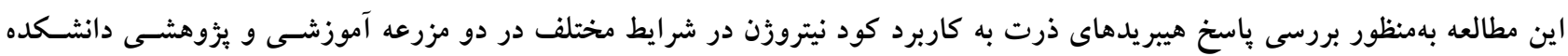

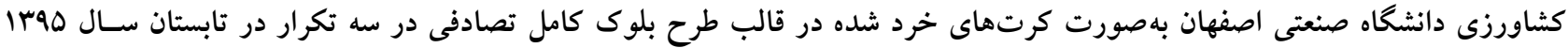

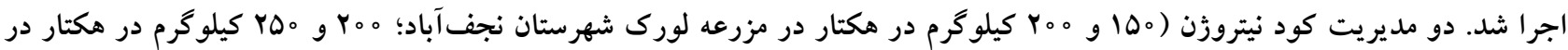

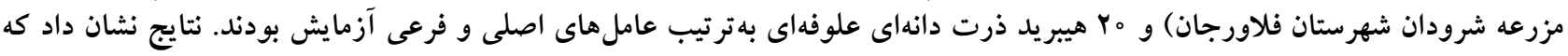

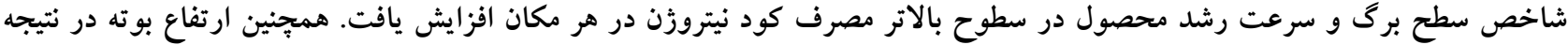

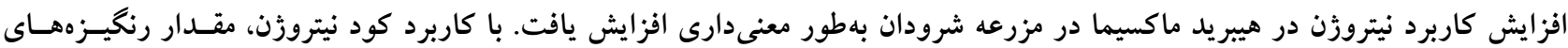

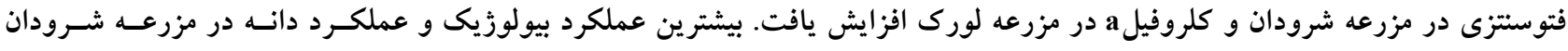

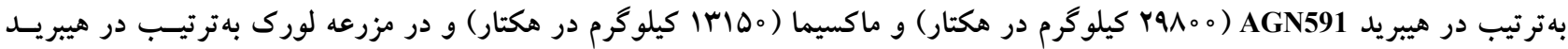

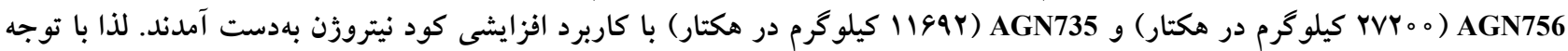

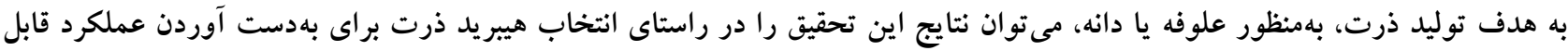

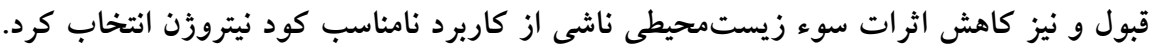

وازههاى كليدى: سرعت رشد محصول، سرعت جذب خالص، غلظت كلروفيلa، نيتروزن، هيبريد ذرت

او ז. ب بهترتيب دانشجوى دكترى و استاديار كروه زراعت و اصلاح نباتات دانشكده كثاورزى دانشكاه ايلام، ايران

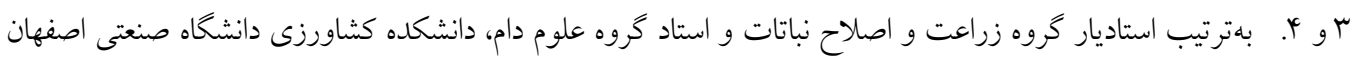

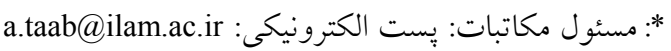




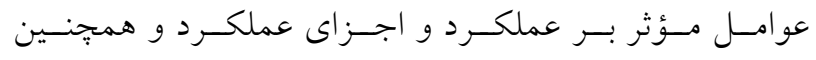

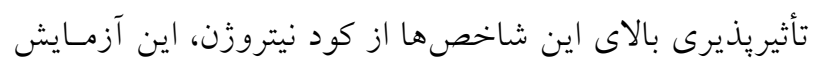

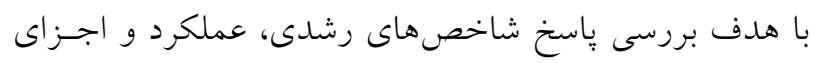

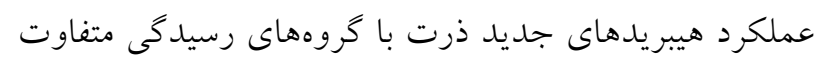

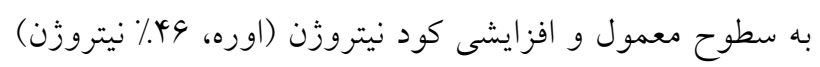

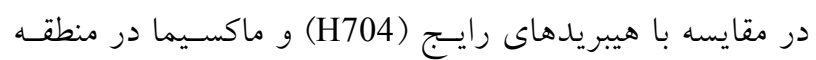

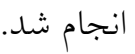

\section{مواد و روشها}

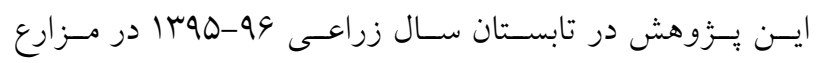

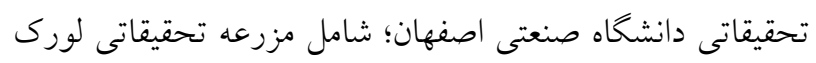

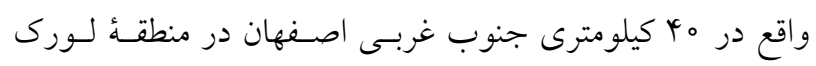

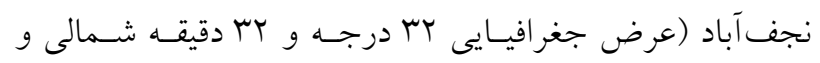
طول جغرافيايى اله درجه وسب دقيقه شـرقى و ارتفـاع از سـطح دريا • DVV متر ) و مزرعه شرودان واقع در مب كيلومترى اصفهان

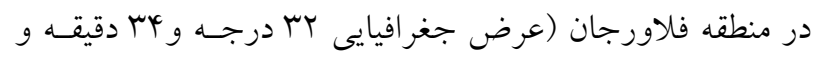

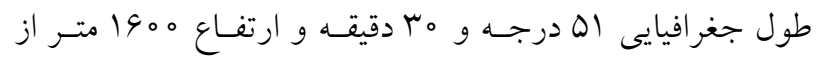
سطح درياهاى آزاد) و در هر ايستخاه بهصورت كرتهاى خـرد

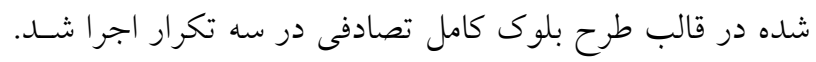

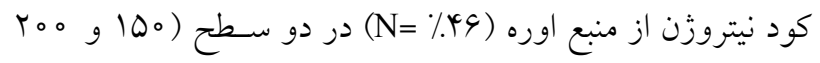

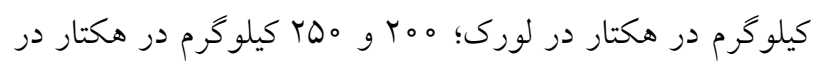

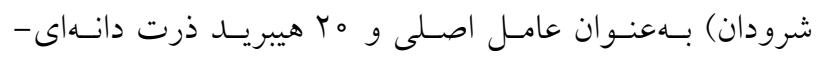

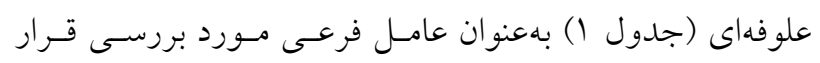
كرفت.

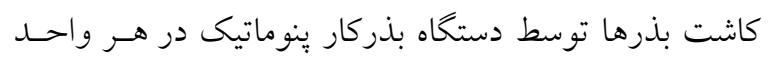

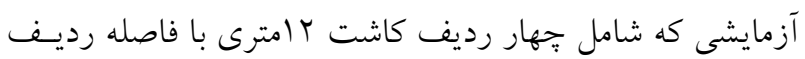

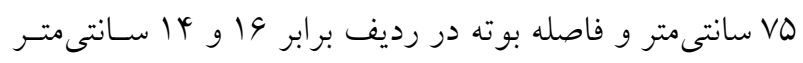

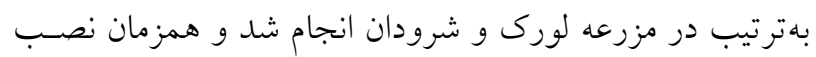
نوارهاى آبيارى قطرهاى از نوع بلى اتيلن درزدار با فاصله روزنه تُونه

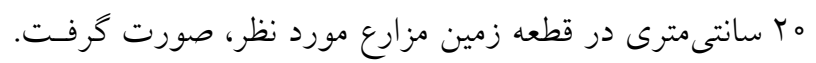

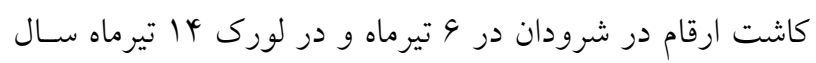

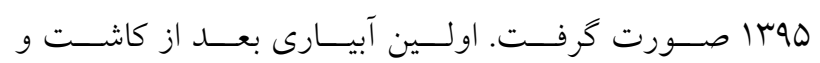

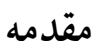

ذرت (Zea mayes L.) بعد از گَنـدم و بــرنج رتبـه سـوم منبـع غذايى براى جمعيت در حال افزايش جهان را بهخود اختصاص

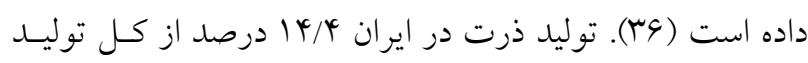
محصولات زراعى را به خود اختصاص داده اسـت. سطح زيسر

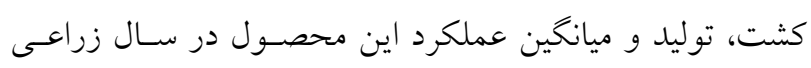

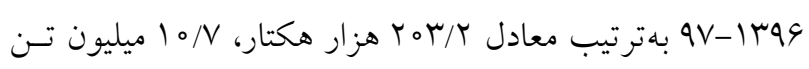

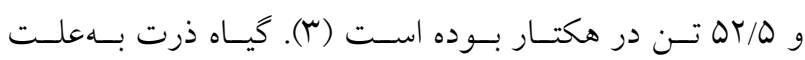

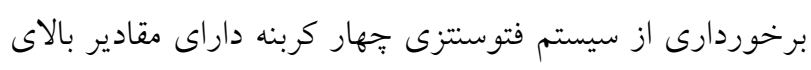

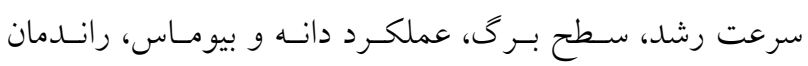

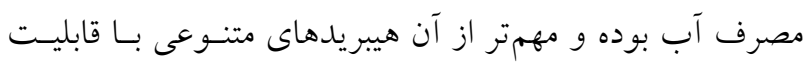

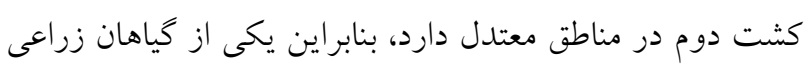

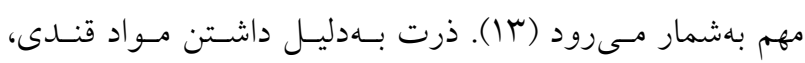

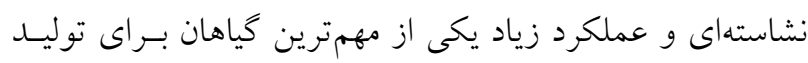

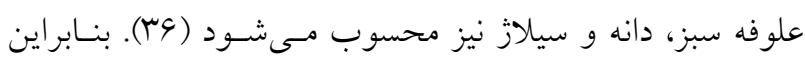

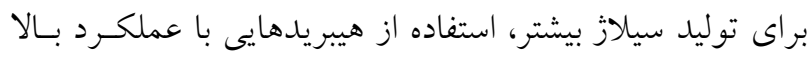
در مقايسه با ارقام رايج در كشور در اولويت قرار دارد.

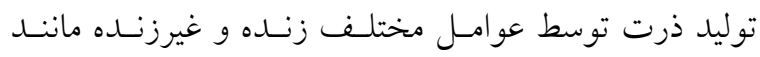

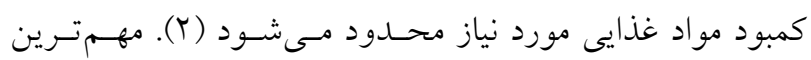

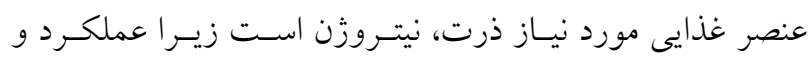

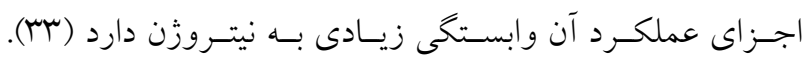

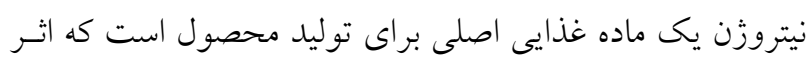

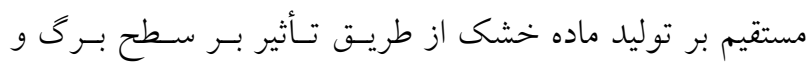

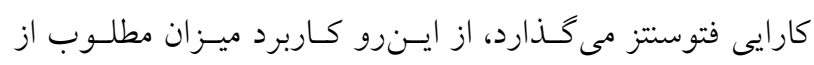

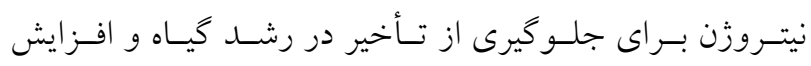

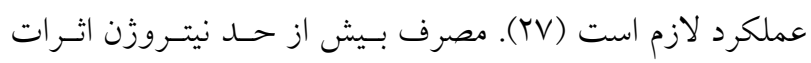

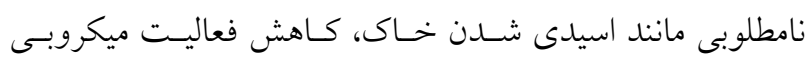

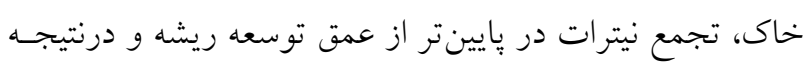

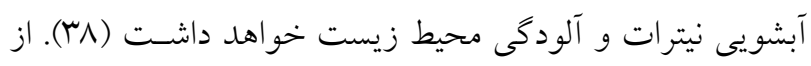

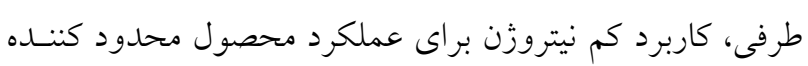
است (rV). با توجه به اهميت شاخصهاى رشدى در تجزيه و تحليل 
جدول ا. برخى ويزگ گهاى هيبريدهاى مورد مطالعه در آزمايش

\begin{tabular}{|c|c|c|c|}
\hline شركت توليد كننده & كروه رسيدگى (FAO) & هيبر يد ذرت & شماره \\
\hline مارتون وشر & FAO 580 (ميان رس) & SC535(Maxima) & 1 \\
\hline شركت امريكن زنتيكس & FAO 700+(ديررس) & AGN 735 & r \\
\hline شركت امريكن زنتيكس & FAO 700 (ديررس) & AGN 756 & r \\
\hline شركت امريكن زنتيكس & FAO 700 (ديررس) & AGN 717 & $r$ \\
\hline شركت امريكن زنتيكس & FAO 700 (ديررس) & AGN 719 & 0 \\
\hline شركت امريكن زنتيكس & FAO 700 (ديررس FAO & AGN 715 & 4 \\
\hline مغان & FAO 700 (ديررس) & 704 & 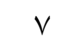 \\
\hline شركت امريكن زنتيكس & +(ديررس)FAO 700+ & AGN 728 & $\wedge$ \\
\hline كن زنتيكس & FAO 700 (ديررس & AGN 798 & 9 \\
\hline شركت امريد & FAO 650 (متوسط رس) & AGN 720 & 10 \\
\hline شركت امريكن زنتيكس & FAO 650 (متوسط رس) & AGN 740 & 11 \\
\hline شركت امري & FAO 700 (ديررس & AGN 722 & ir \\
\hline شركت امريكن زُنتيكس & FAO 650 (متوسط رس) & AGN 794 & ir \\
\hline شركت امريكن زُنتيكس & FAO 600 (متوسط رس) & Whchita & 14 \\
\hline شركت امريكن زُنتيكس & FAO 600 (متوسط رب & AGN 625 & 10 \\
\hline شركت امريكن زُنتيكس & FAO 600 (متوسط رس) & Jolli & 19 \\
\hline شركت امريكن زُنتيكس & FAO 600 (متوسط رس) & AGN 555 & IV \\
\hline شركت امريكن زُنتيكس & FAO 600 (متوسط رس) & AGN 642 & $1 \wedge$ \\
\hline شركت امريكن زُنتيكس & FAO 500 (ميان رس) & AGN 591 & 19 \\
\hline شركت امريكن زُنتيكس & FAO 500 (ميان رس) & AGN 520 & ro \\
\hline
\end{tabular}

بهمنظور تعيين شـاخص هـاى فيزيولوزيـك رشــ، يـنج مرحلـه

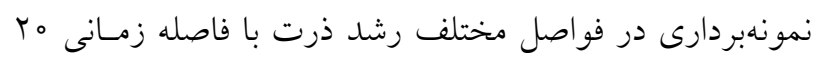
روز از تاريخ كاشت در دو مكان انجـام شـد. در هـر مرحلـه از نمونهبردارى بنج بوته انتخاب و يُ إز انتقال به آزمايشـاه بـهـ

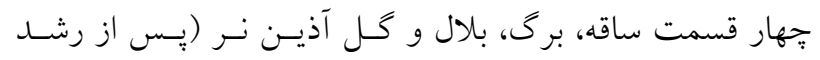
زايشى) تفكيك شدند. براى اندازهگيرى وزن خشك انـدامهـاى

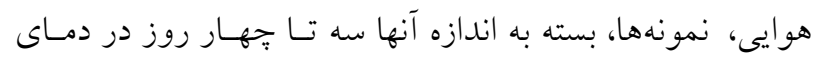

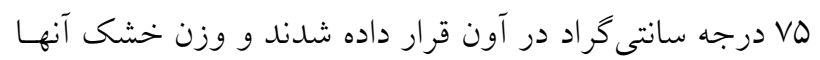
محاسبه شد. براى اندازه گيرى شاخص هاى رشد از روابـط زيـر

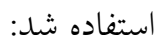

$\mathrm{RGR}=(\ln \mathrm{W} 2-\ln \mathrm{W} 1) /(\mathrm{T} 2-\mathrm{T} 1)$
آبيارىهاى بعدى در طول دوره رشد و بر اساس شرايط محيطى

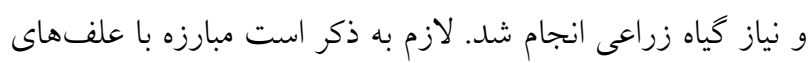
هرز بـا اسـتفاده از علـفــش آتـرازين (سـاخت شـركت گيـاه) بهصورت بيش كاشتى و همجنين استفاده از علـفـكش اسـتوكلر (ساخت شركت شيما گرو يزد) به مقــدار يـنج ليتـر در هكتـار در

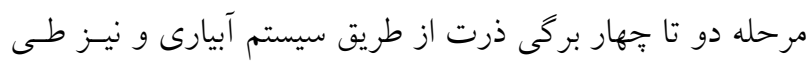

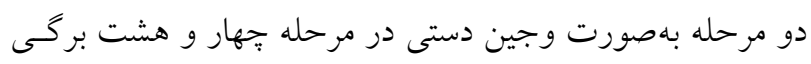

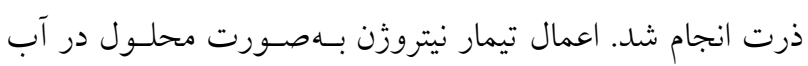
آبيارى در مرحله سه تا جههار بركى ذرت، مرحلـه سـاقه رفـتن و

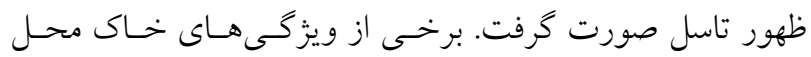
اجراى آزمايش دو مزرعه در جدول ب ارائه شده است. 
جدول Y. برخى ويزّى هاى فيزيكى و شيميايى عمق •r-ه سانتىمترى خاك محل آزمايشها

\begin{tabular}{|c|c|c|c|c|c|c|c|c|c|c|}
\hline هدايت الكتريكى & يتاسيم & فسفر & $\mathrm{pH}$ & نيتروزن & ماده آلى & رس & سيلت & شن & \multirow[t]{2}{*}{ بافت خاى } & \multirow[t]{2}{*}{ مكان } \\
\hline$\left(\mathrm{dS} \mathrm{m}^{-1}\right)$ & \multicolumn{2}{|c|}{$\left(\mathrm{mg} \mathrm{kg}^{-1}\right)$} & - & & & $\%)$ & & & & \\
\hline$T / W V$ & $r \Delta \circ / \wedge \Delta$ & $r \Delta / \circ D$ & $V / 09$ & $\circ / \circ \wedge$ & o/N & rA & $Y \% / 0$ & rY/O。 & لومى رسى & لورى \\
\hline $1 / 0 \%$ & rq1/1. & $\Delta \psi / \Lambda \Delta$ & $N / Y G$ & $\circ / \Lambda$ & $1 / \mathrm{VA}$ & rV & $r V / Q 0$ & $r Q / 90$ & لومى رسى & شرو دان \\
\hline
\end{tabular}

همجنـين تجزيـه واريـانس (در دو منطقـه لـورك و شـرودان)

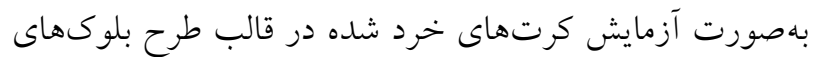
كامل تصادفى با استفاده از نرمافزار SAS نسخه هُ4 انجام شــــ

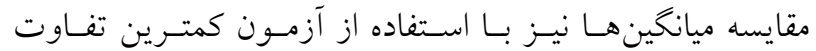
معنى دار (LSD) در سطح احتمال بنج درصد انجام شد.

نتايج و بحث سرعت جذب خالص (NAR)

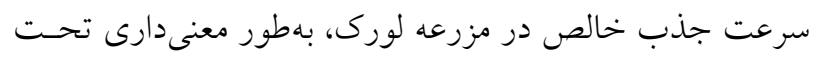

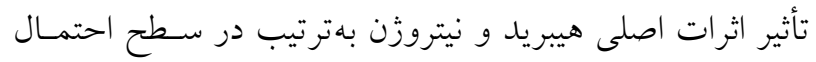

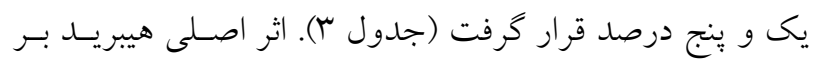

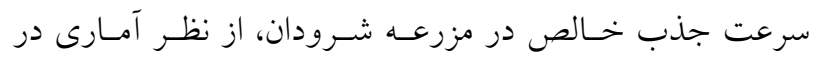

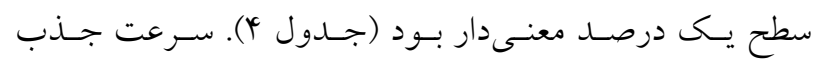

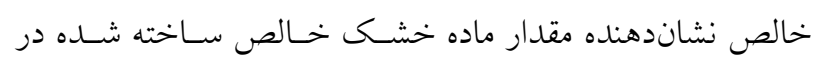

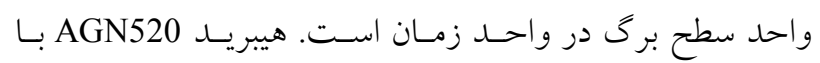

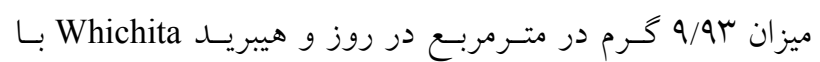

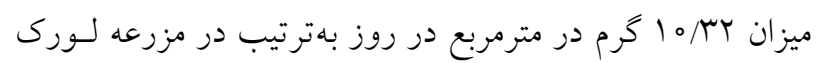

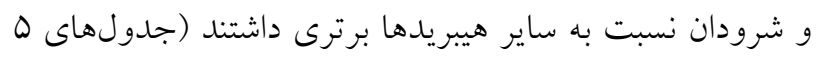

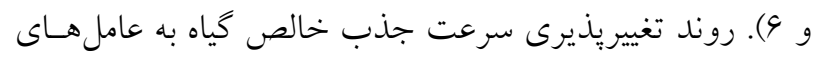

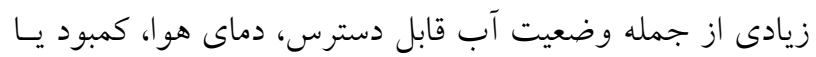
كفايت مواد غذايى مورد نياز بستخى دارد، با وجود ايسن كـاربرد

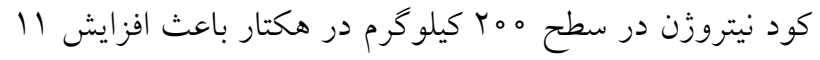

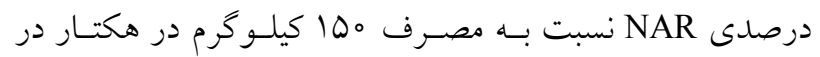
منطقه لورى شد (جدول Q). ساجدى و اردكانى (Yr) بـه نقشـ

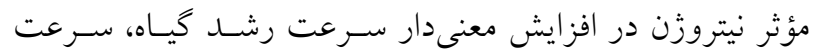
رشد نسبى و سرعت جذب خالص اشـاره كـردانـــ. بـهــلاوه
$\mathrm{NAR}=\mathrm{CGR} / \mathrm{LAI}$

$\mathrm{LAI}=[(\mathrm{LA} 2+\mathrm{LA} 1) *(1 / \mathrm{GA})$

$\mathrm{CGR}=[(\mathrm{W} 2-\mathrm{W} 1) /(\mathrm{T} 2-\mathrm{T} 1)]^{*}(1 / \mathrm{GA})$

در اين روابـط RGR: سـرعت رشــ نسببى، NAR: سـرعت

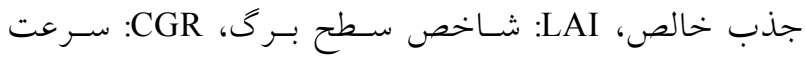

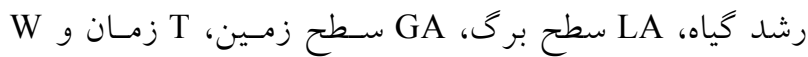
وزن خشك كياه است. بهمنظور اندازهيرى شـاخص سطح برى در هر مرحله نمونهبردارى بهروش تخريبى و برگهاى

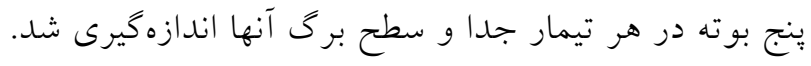

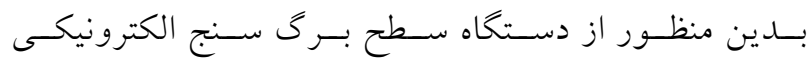
(Model Winarea-ut-11 made in Iran)

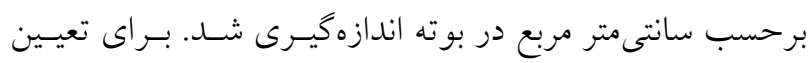

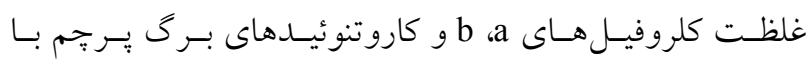

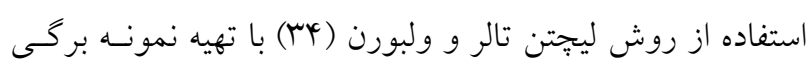

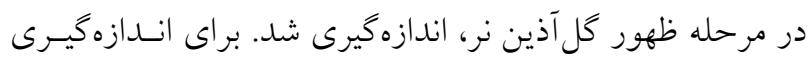

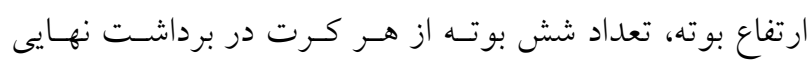

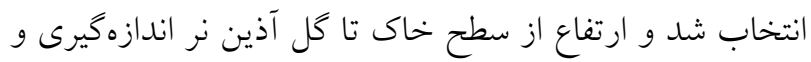

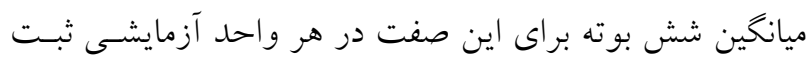

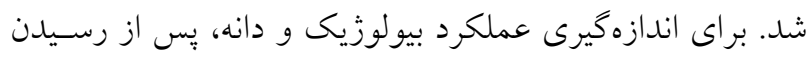

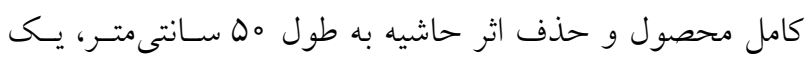
مترمربع از خطوط وسط در هر واحـــــ آزمـايش برداشـت شـــــ

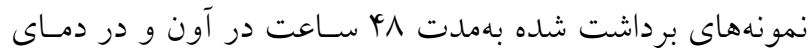

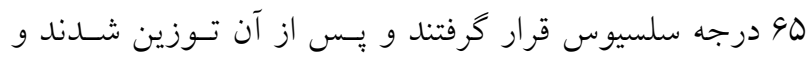
سبس عملكرد بيولوزيك مشخص شد، در ادامه تعـداد دانـه در بلال، وزن هزار دانه و عملكرد دانه اندازهيرى شدند. 


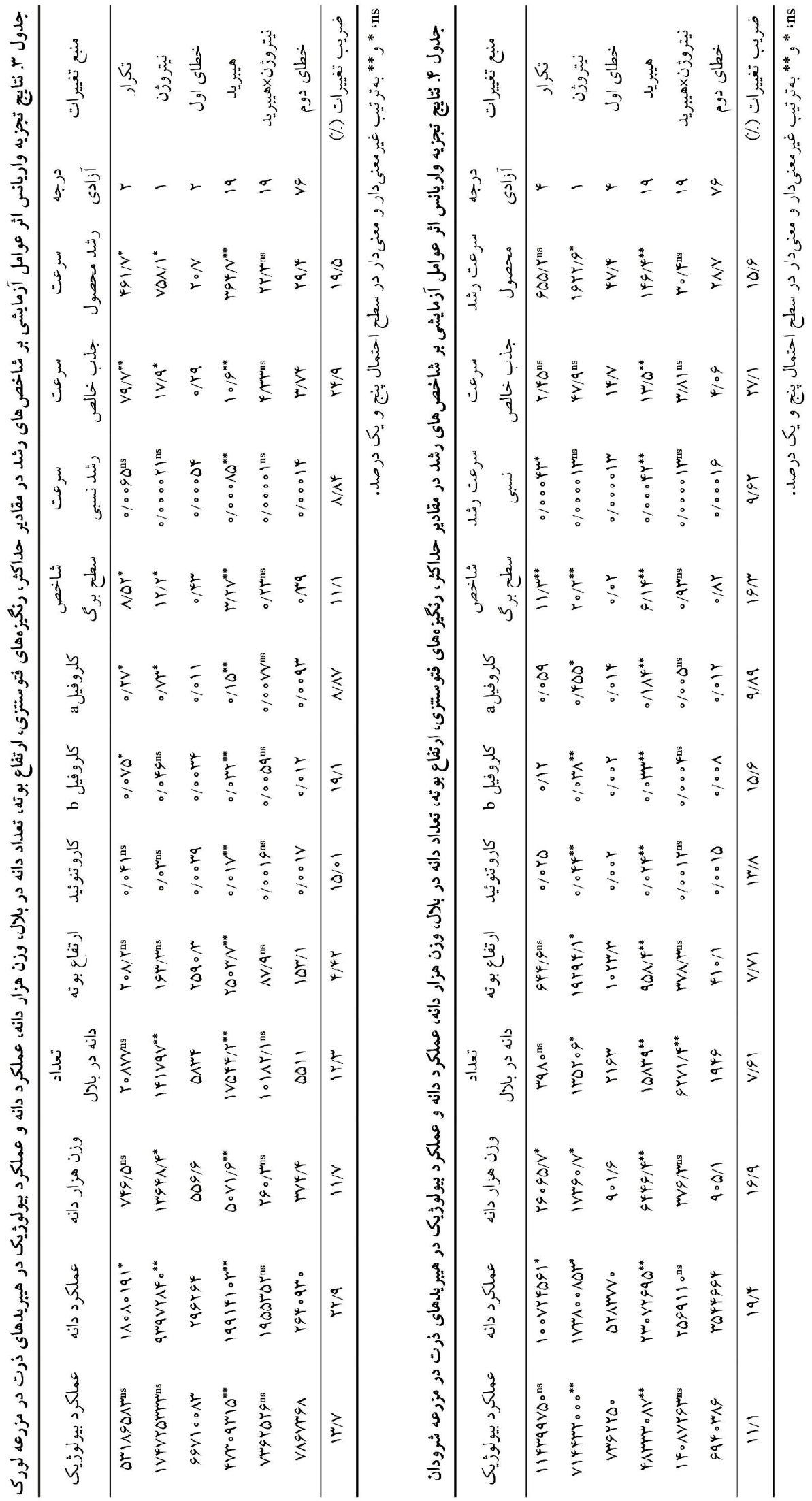




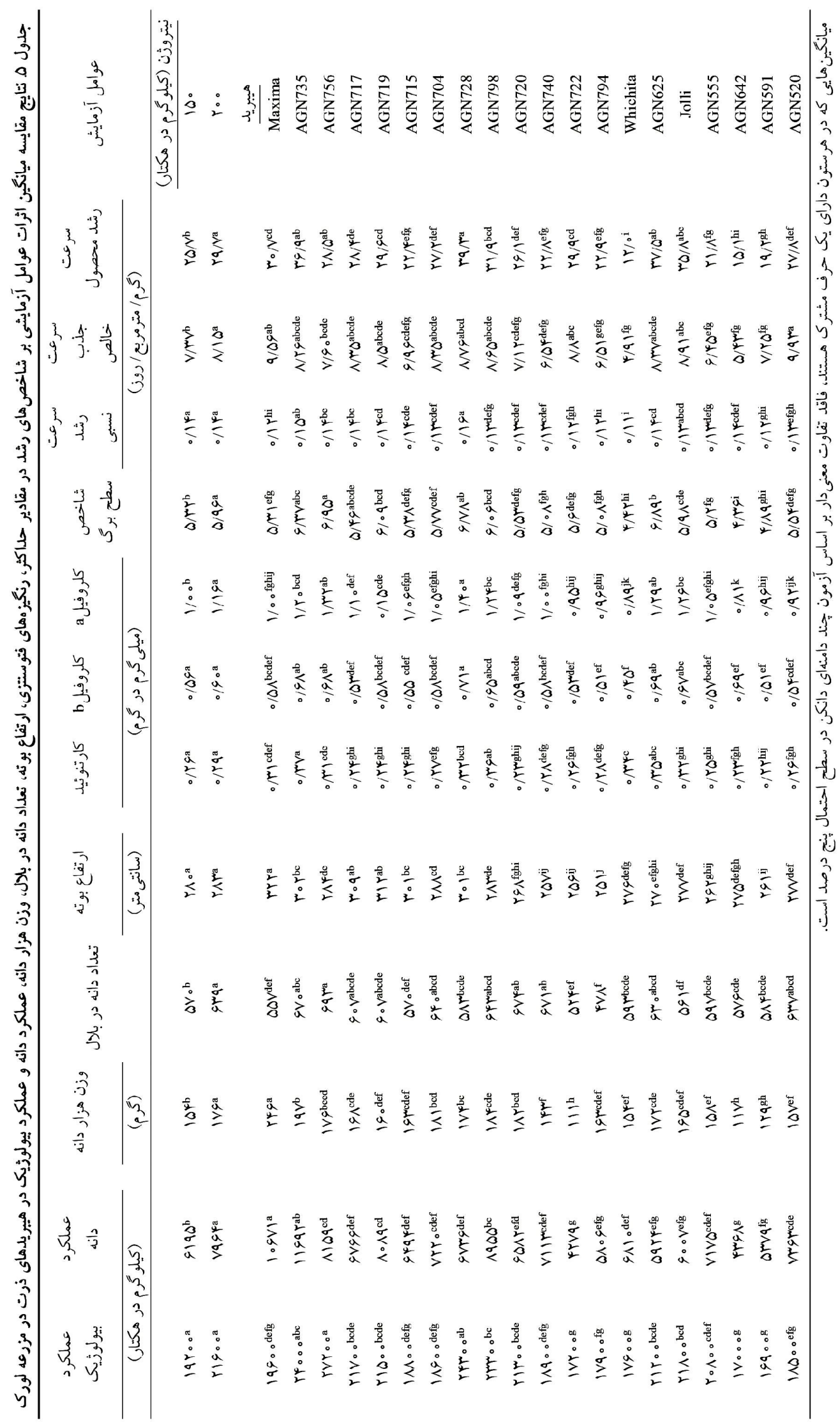




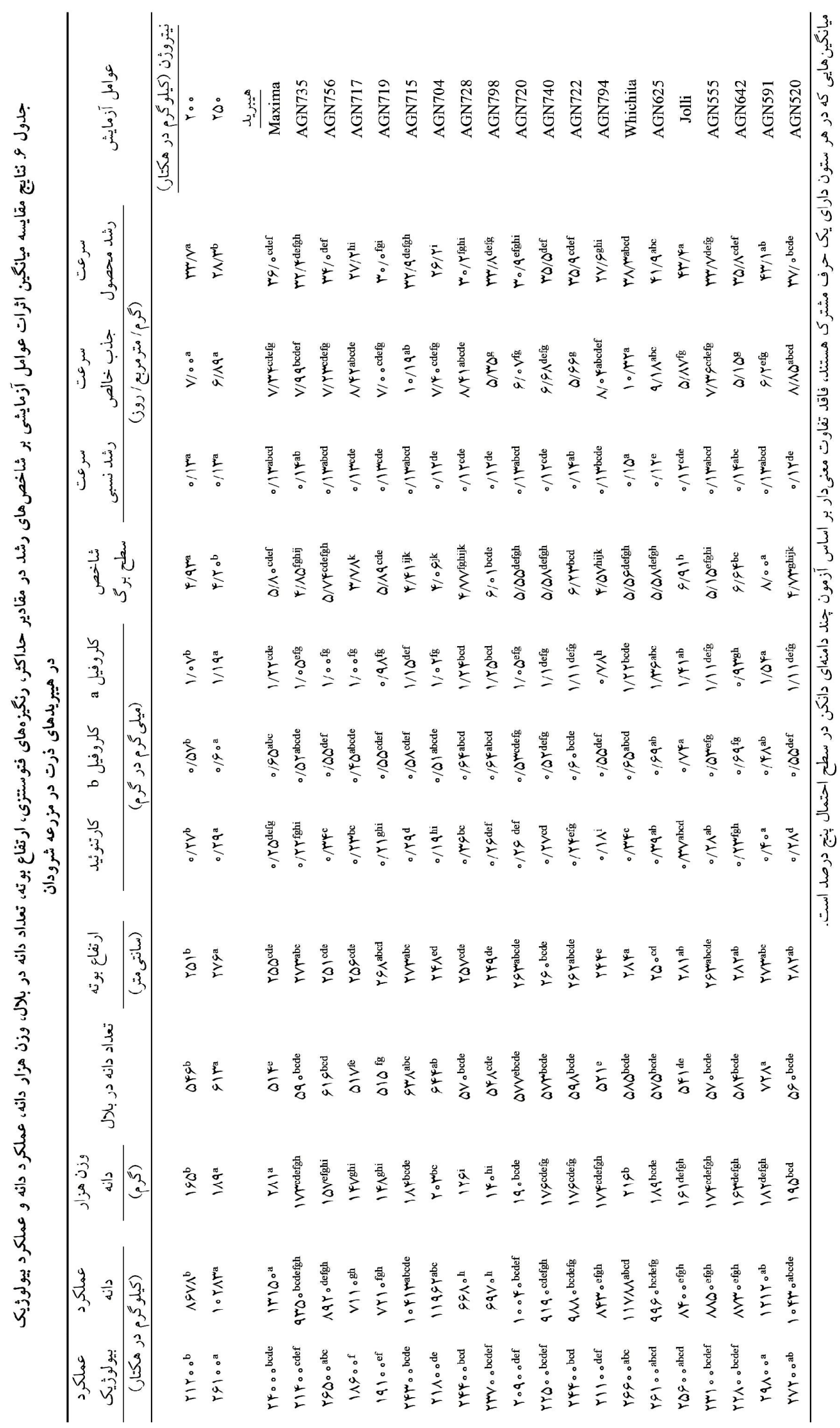


قابل توجه سرعت رشد كيـاه و شـاخص سـطح بـرى در ذرت

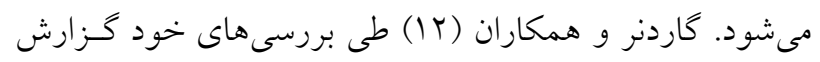

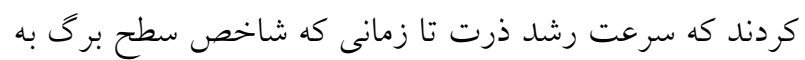

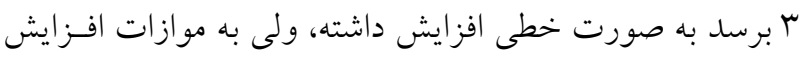

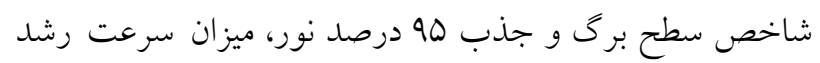

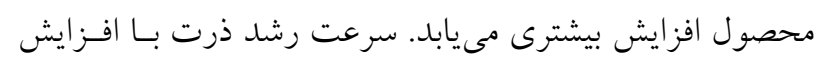

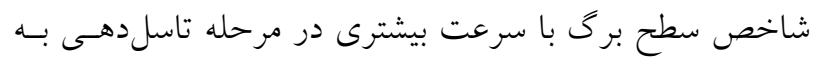

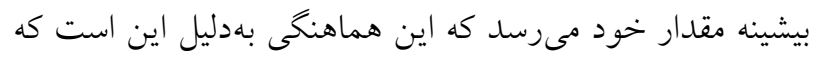

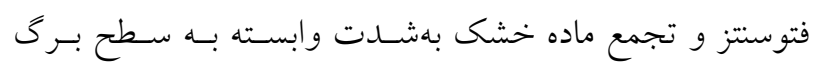

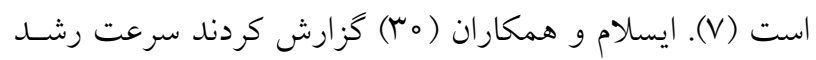

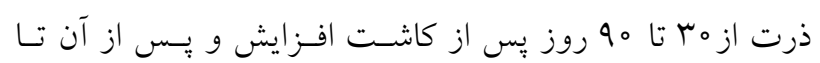

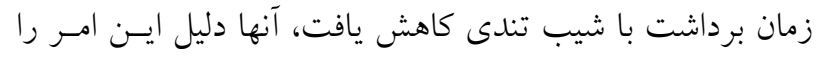

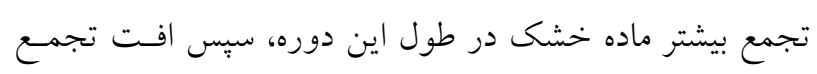

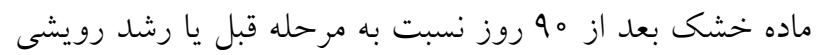
عنوان كردند. - ماده

سرعت رشد نسبى(RGR) اثر هيبريد بر سرعت رشد نسبى از نظر آمارى در سطح احتمـال

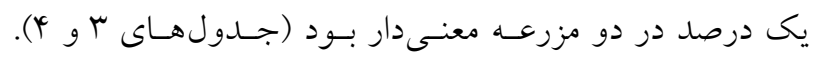

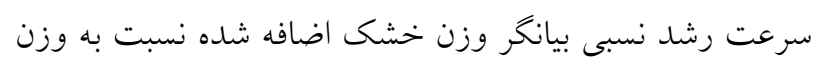

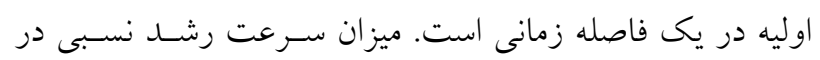

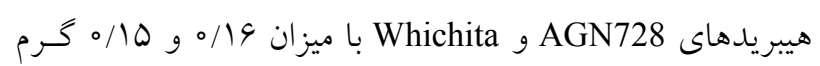

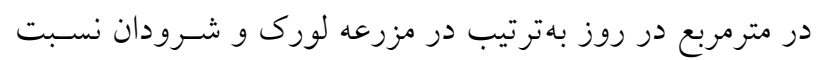

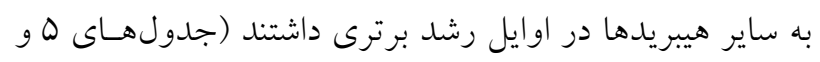

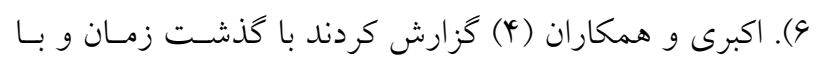

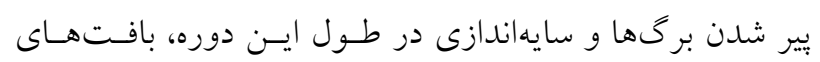

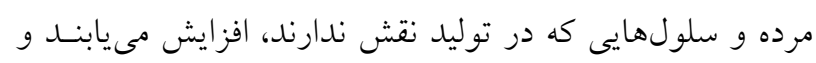

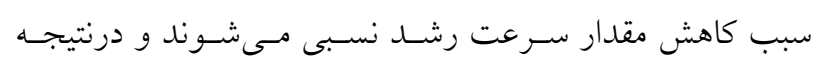

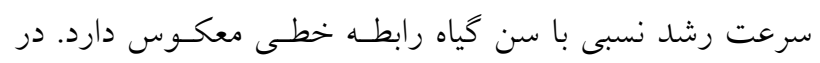

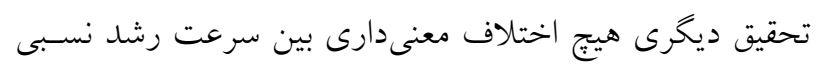

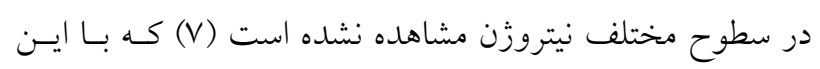
نتايج مطابقت دارد.
نشان دادند كه سرعت جذب خالص، در مرحلـه تاسـلدهـى و

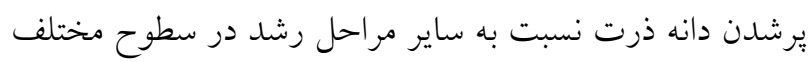
نيتروزن بيشينه است.

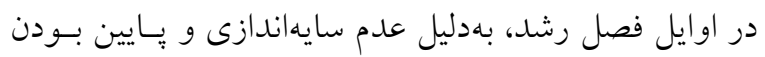

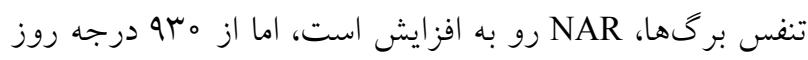

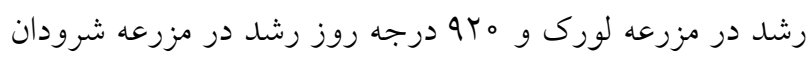

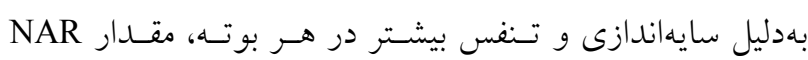

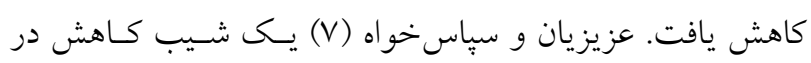

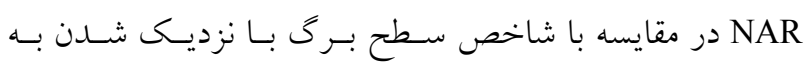

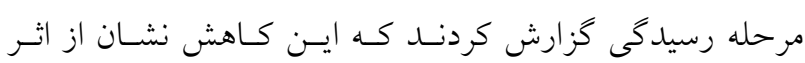

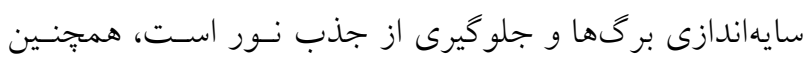

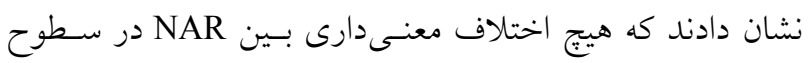
مختلف نيتروزن وجود ندارد كه با نتايج اين تحقيـق در مزرعـه دئس شرودان مطابقت دارد.

\section{سرعت رشد محصول (CGR)}

اثر اصلى نيتروزن و هيبريد بر سرعت رشد محصول مدول از نظـر

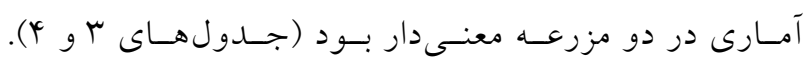

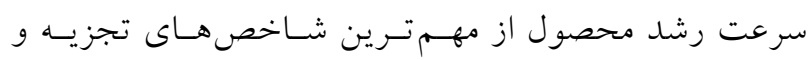

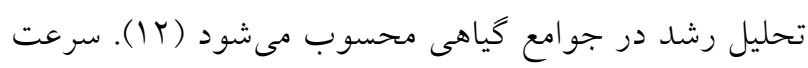

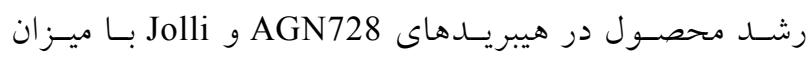
ه لورى و شرودان بهطور معنى دارى بيشتر از سـاير هيبريــدها

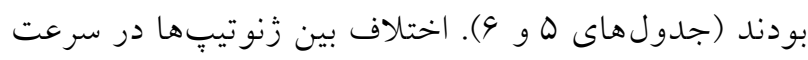

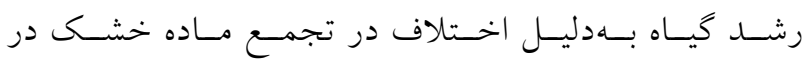
زنوتيبٍ هاى مختلف است. نتايج مشابهى توسط يُزوهشكران ديخر نيز ارائه شده است (ه).

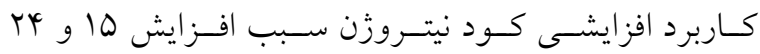
درصدى سرعت رشد محصـول بـهترتيـب در مزرعسه لـورى و شرودان در مقايسه با مصرف كمتر نيتروزن شد (جدولهاى هـ و

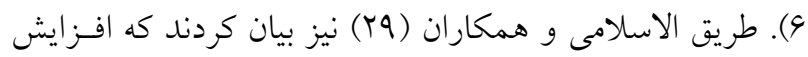

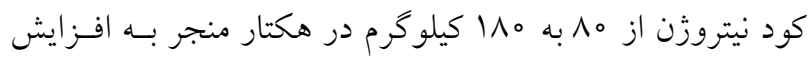


ميلى گرم در گرم وزنتـر بـهـترتيـب در هيبريـدهاى AGN591، Jolli و AGN591 مشاهده شد (جدولهاى ه و 9). كاربرد افزايشى كود نيتروزن نسبت به ميزان مصـرف كمتـر،

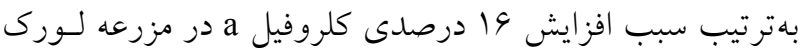

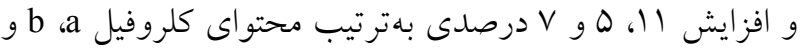
كاروتنوئيد در مزرعه شرودان شد كه ايـن موضـوع بيـان كنتــهـ

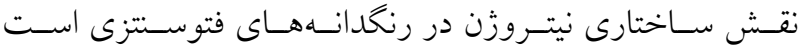
(جدولهاى ه و 9). نيتروزن نقش اساسى در سـاخت كلروفيـل دارد (19). در شرايط كمبود نيتروزن، آنزيم فسـفوانول بيــروات

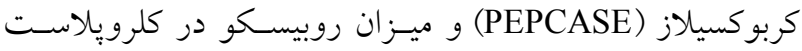

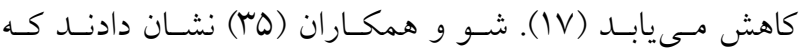
هدايت روزنهاى (gs) و ميزان فتوسنتز (Pn) تحت تنش كمبـود

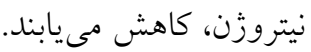
ميرزاخانى (1) در مطالعه بررسى اثر كود سرك نيتروزن بر

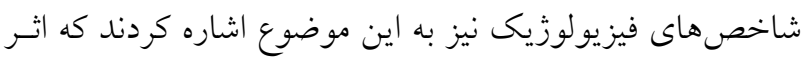

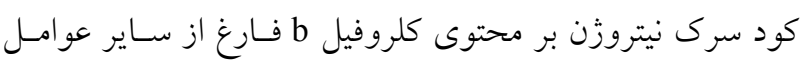
آزمايشى مثبت و معنى دار بود. همجنين ملكى و همكـاران (19) به اين نتيجه رسيدند كه با كاربرد مختلف كـود نيتـروزن مقــــار

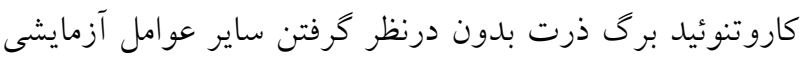

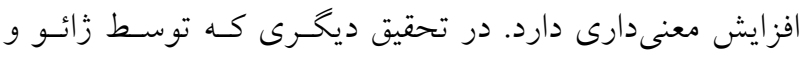

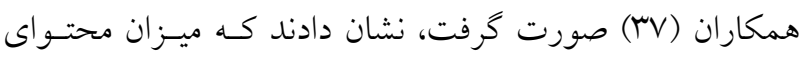

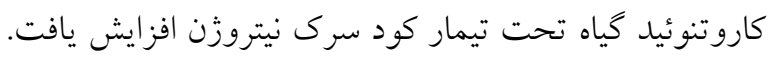

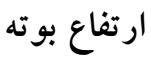
اثر هيبريد در مزرعه لـورك و اثـــ هيبريســ و نيتـروزن در مزرعـهـ

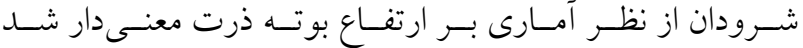

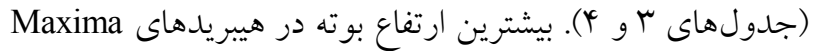

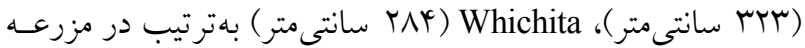
لـورك و شـرودان مشــاهده شـــ (جـــولهــاى ه و 9). كـاربرد افزايشى كود نيتروزن، سبب افزايش ه ا ا درصدى در ارتفـاع بوتسه

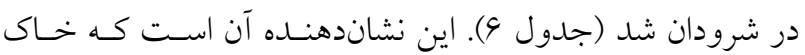

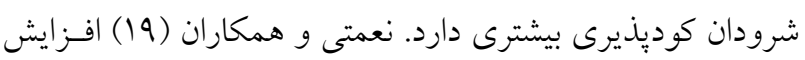

شاخص سطح برى (LAI)

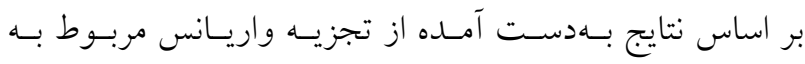

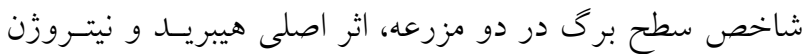
بر اين شاخص از نظر آمارى معنى دار شد (جدولهـاى بَ و †). بيشترين شاخص سطح برى در هيبريـدهاى AGN756 (9/90)

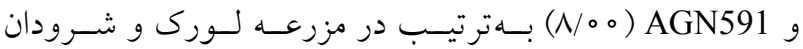
مشاهده شد (جدولهاى ه و 9). اختلاف هـاى عملكـردى بـين هيبريدها بهطور قابل توجهى به دليـل دوره طـولانىتـر جـــب

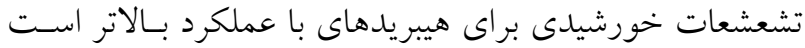
(r). اين شاخص در مراحل ابتدايى رشد بوتهها و توسعه شاخ و برى در كياه كم بوده ولى با كذشت زمان در مزرعه لـورك و

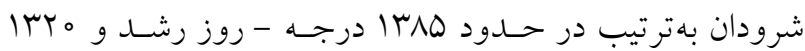
درجه - روز رشد به بيشـينه خـود رسـيد و بعـا از آن كـاهش

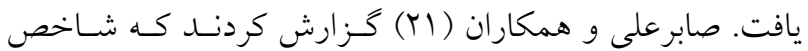

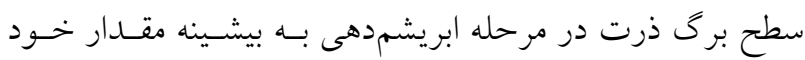

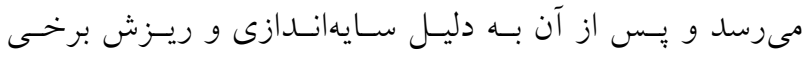

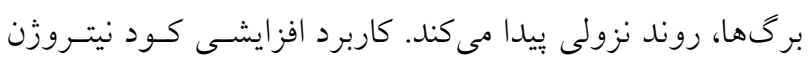
بهترتيب، افزايش rا و و 19 درصدى اين شـاخص را نسـبت بــه مصرف كمتر كود نيتروزن در مزرعه لورى و شرودان بـه دنبـال داشت (جدولهاى ه و 9). اسلام و همكـاران (9) و تـاجول و

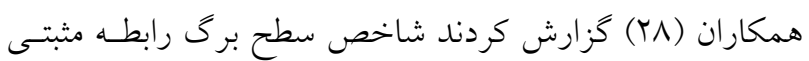
با كاربرد كود نيتروزن در ذرت دارد.

\section{غلظت كلروفيل و كاروتنوئيد}

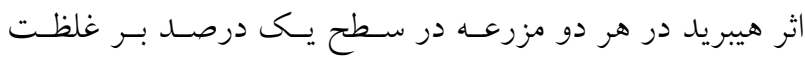

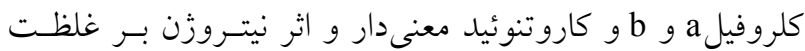

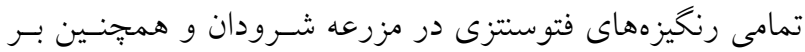

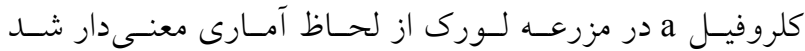

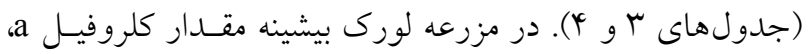

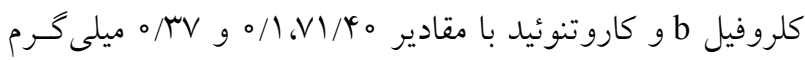

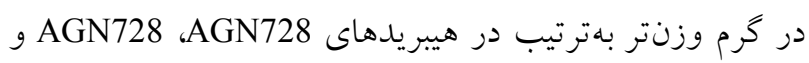

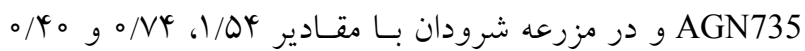


هيبريد قرار گرفت. در بين هيبريدهاى مورد آزمايش، بيشـترين وزن

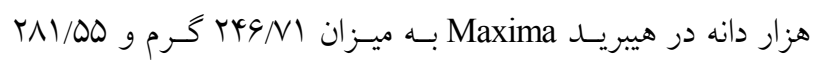
كرم بهترتيب در مزرعه لورى و شرودان بود (جدولهاى هو و ه). كـاربرد افزايشـى كـود نيتـروزن در دو مكــان، افـزايش ها درصدى در وزن هزار دانـه را نشـان داد (جـدولهـاى هو و 9). كمبود نيتروزن، عملكرد دانه ذرت را از راه كاهش وزن و تعداد دانه، كاهش مىدهد (11). نيتروزن باعث افزايش سهم مواد نــور ساختى در ير شدن دانهها، افزايش وزن هزار دانه و شـمار دانـه

$$
\text { در بلال مى شود (Yo) (ro). }
$$

\section{عملكرد دانه} اثر هيبريد در مزرعه لورك و اثر هيبريــــ و نيتـروزن در مزرعـه

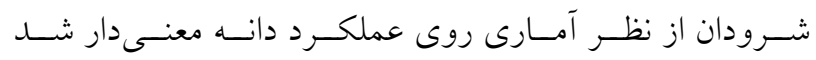
(جدولهاى ץو \& أ). در بين هيبريدهاى مورد آزمايش، بيشـرين

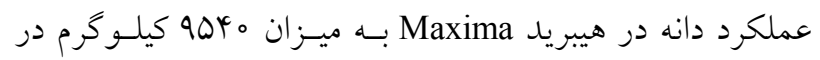
هكتار و •Dا آ كيلوكرم در هكتار بهترتيب در مزرعه لـورى و

شرودان مشاهده شد (جدولهاى هو 9). بوراس و كامبين (9) بيان كردند، عملكرد دانه حاصل تعداد دانه در واحسـ سـطح و ميـانخين وزن دانـه اسـت. كـاربرد م كيلو گرم در هكتار كود نيتروزن، افزايش 1 ا درصسـى را نسـبت به مصرف ه r كيلو گرم در هكتار روى اين شاخص در مزرعسه شرودان نشان داد (جدولهاى ه و 9). افزايش در ميزان نيتروزن مصرفى، باعث افزايش در تعداد بلال و دانه و درنتيجه افـزايش

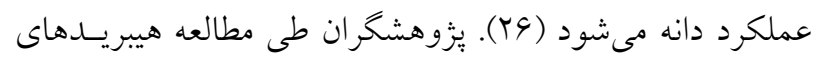
مختلف دريافتند كه كود نيتروزن بهطور معنىدارى عملكرد دانه در بوته در واحد سطح را افزايش مىدهد (YY). ياسخ هيبريدهاى مختلف ذرت به نيتروزن مصرفى و شـرايط محيطى محل اجراى آزمايش وابسته است. اين شرايط شـامل آب و هوا، خاك و مديريت در دو مزرعه مورد ارزيابى اسـت. از نظـر وضعيت خاك، در هر دو منطقه بافت خاك لومى - رسى بود. بنابراين با مديريت افزايشى كود نيتـروزن، تـاريخ كاشـت و شرايط دمايى بهتر در مزرعه شرودان، نزديـك VV درصـد بـراى

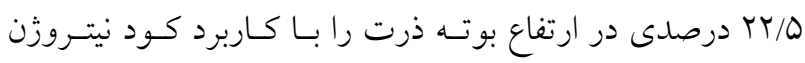
كزارش كردند. ارتفاع گياه، شاخص سطح برى و عملكـرد بـلال بهور معنى دارى تحت تأثير مصرف نيتروزن قرار مى گيرند (10).

\section{تعداد دانه در بلال}

بنابر نتايج ارائه شده در جدولها (باو †) شاخص تعداد دانه در بلال بهطور معنسىدارى تحــت تـأثير نيتـروزن و هيبريــا در دو مزرعه قرار گرفتند. بهطور كلى بيشترين شمار دانـه در بـالال در هيبريد AGN756، هيبريــ AGN756 (994 دانـه) و AGN591

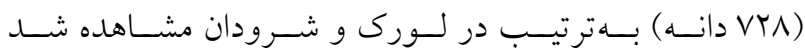
(جدولهاى ه و 9). اثر متقابـل نيتـروزن در هيبريـــ در مزرعـه شرودان معنى دار بود. تعداد دانـه در بــلال وابسـته بـه يتانسـيل زنتيكى گياه و در دسترس بودن مــواد مغـذى در مراحـل رشـــ رويشى، زايشى گياه و شكل گيرى گل آذيننر است (1). كاهش تعداد دانه بهدليل كاهش ظرفيت مقصد فيزيولوزيك اثر مستـقيم بر عملكرد دانه دارد.

كاربرد افزايشى كود نيتـروزن، افـزايش با درصــى تعـداد دانه در بلال را نسبت به ميزان مصرف كمتر كود نيتروزن در دو مزرعه نشان داد (جدولهاى ه و 9). كاهش تعداد دانه در بـلال ممكن است بر اثر تأخير در ظهور كاكل و يا سقط جنين در اثـر كمبود هيدراتهاى كربن باشد (سY). خان و همكـاران (ها) در مطالعه خود بيان كردند كه تعداد دانه در بلال تحت تأثير هيبريد و نيتروزن قرار مى گيرد و با افزايش كاربرد كـود نيتـروزن (هـ كيلوكرم در هكتار) بيشترين تعداد دانه در بلال مشاهده مىشود. در صورت فراهم نبـودن نيتـروزن در مرحلـه گـلـدهـى تعـداد كلهاى تلقيح يافته را كاهش يا دانههاى تشـكيل شــده بـهدليـل كمبود مواد غذايى سقط مىشوند و درنتيجه تعداد دانـه كمتـرى

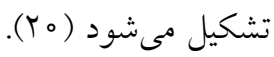
وزن هزار دانه بنابر نتايج به دست آمده (جــدولهـاى با و أ)، وزن هـزار دانـه در ذرت در دو مزرعه بهطور معنى دارى تحت تـأثير سـطح نيتـروزن و 
roD با توجه به نتايج، كاربرد افزايشى كـود نيتـروزن بـهـ ميـزان

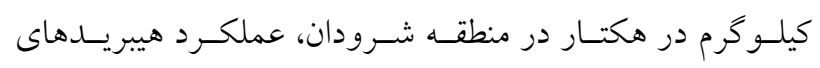

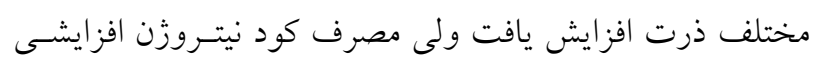

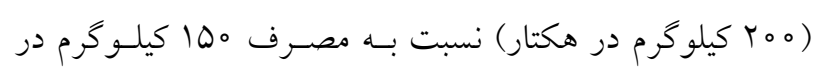

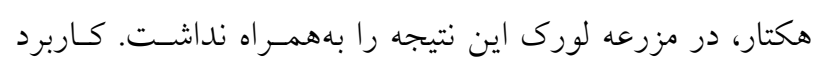

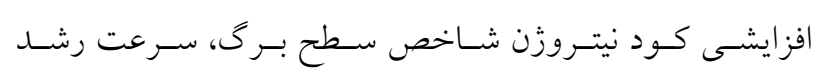

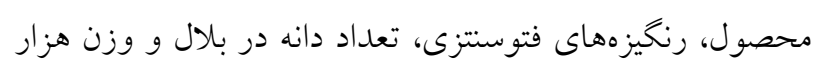

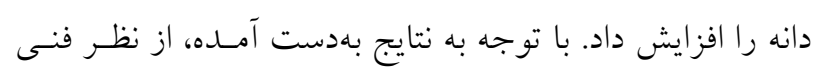

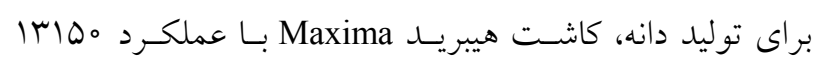

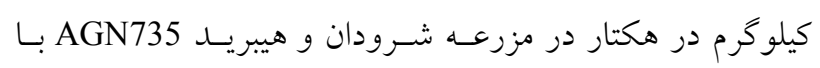

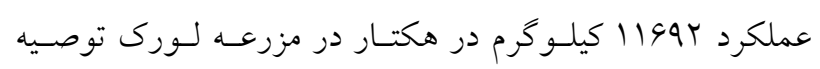

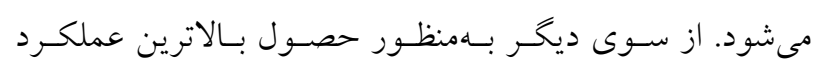

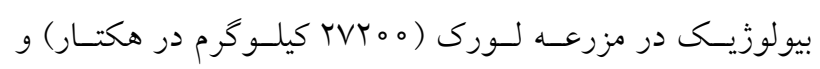

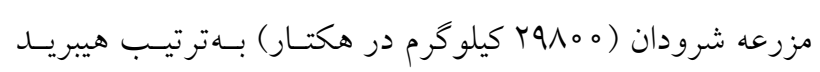

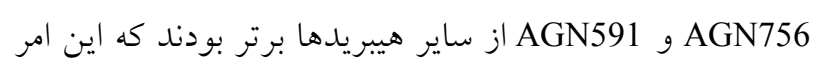

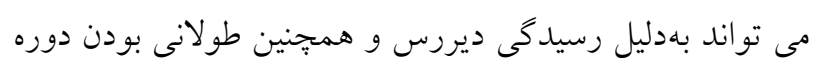
رشد و در نتيجه فرصت ماده سازى و رشد بيشتر اين هيبريـدها

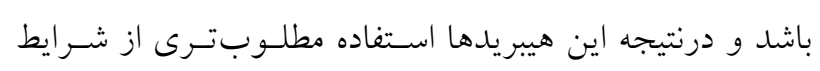

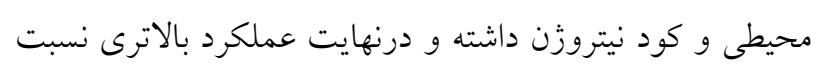
به ساير هيبر يدها نشان دادند.

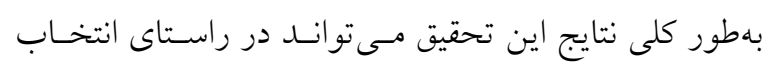

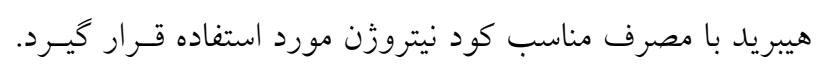

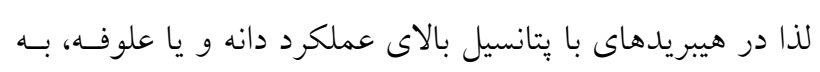

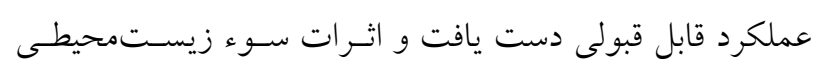

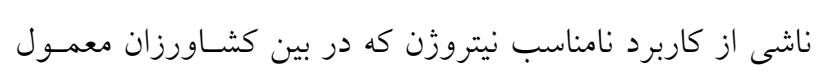

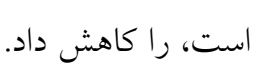

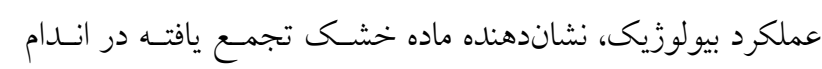

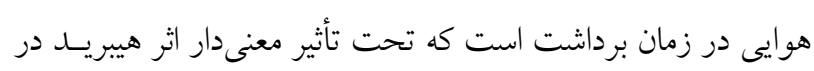

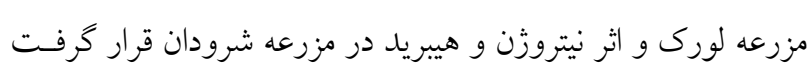

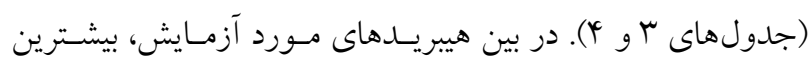

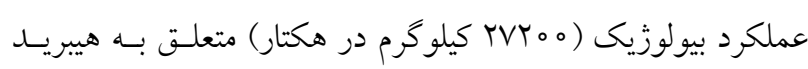

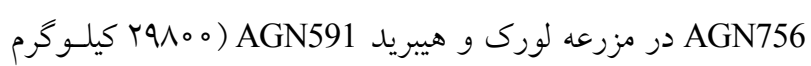

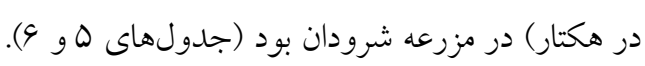

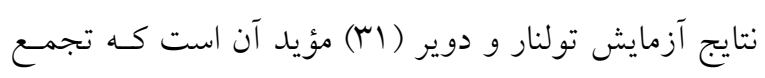

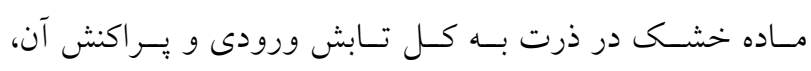

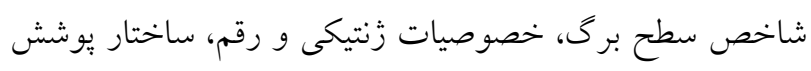

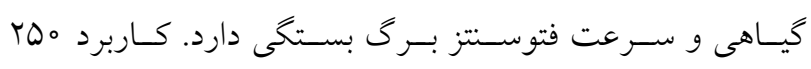

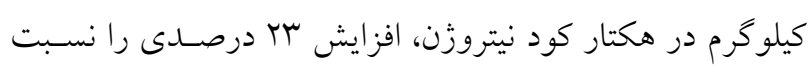

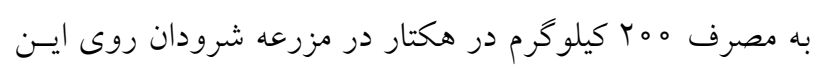

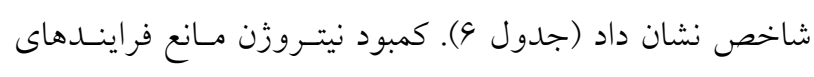

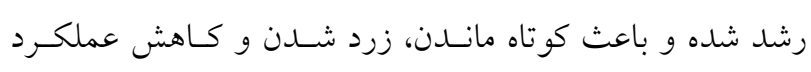

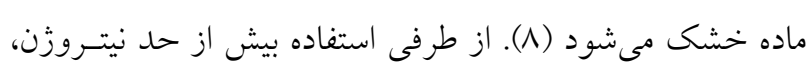

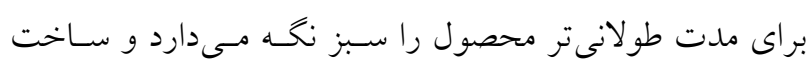

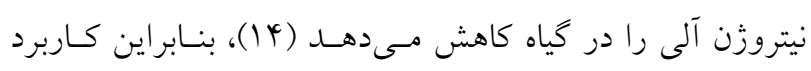

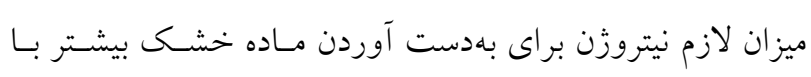

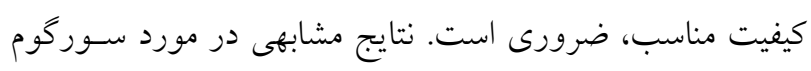

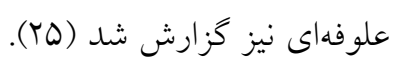

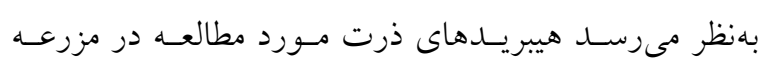

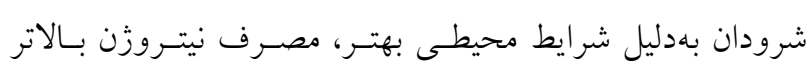

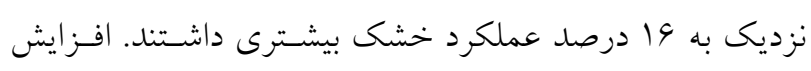

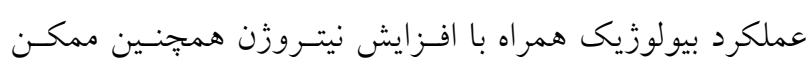

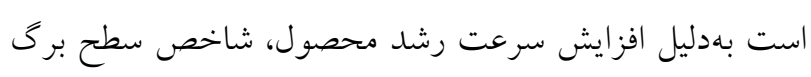

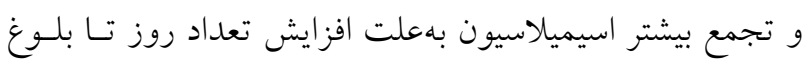

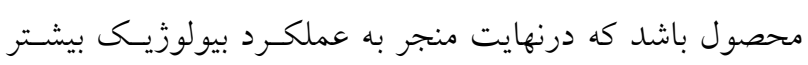


1. Abayomi, Y. A. and G. A. Adedoyin. 2004. Effects of planting dates and nitrogen fertilizer application on growth and yield of contrasting genotypes of maize (Zea mays L.) I: Leaf growth and its relationship with grain yield. Jornal Agricultural Research Development 3(1): 83-98.

2. Achiri, D. T., M. H. Mbaatoh and D. Njualem. 2017. Agronomic and yield parameters of CHC202 maize (Zea mays L) variety influenced by different doses of chemical fertilizer (NPK) in Bali Nyonga, North West Region Cameroon. Asian Journal of Soil Science and Plant Nutrition 2(4): 1-9.

3. Agricultural Statistics. 2019. Department of Planning and Economy. Available online at: http://www.maj.ir. Accessed 25 April 2019.

4. Akbari, G., M. Ghorchiani, H. A. Alikhani, I. Allahdadi and M. Zarei. 2012. Effect of biological and chemical phosphate fertilizers on growth indices and grain yield of maize under deficit irrigation conditions in Karaj region. Iranian Journal of Water and Soil Conservation 22: 51-67. (In Farsi).

5. Aliu, S., S. Fetahu and L. Rozman. 2010. Variation of physiological traits and yield components of some maize hybrid (Zea mays L.) in agroecological conditions of Kosovo. Acta Agriculturae Slovenica 95(1): 35-41.

6. Aslam, M., A. Iqbal, M. I. Zamir, M. Mubeen and M. Amin. 2011. Effect of different nitrogen levels and seed rates on yield and quality of maize fodder. Crop and Environment 2(2): 47-51.

7. Azizian, A. and A. R. Sepaskhah. 2014. Maize response to water, salinity and nitrogen levels: physiological growth parameters and gas exchange. International Journal of Plant Production 8(1): 131-162.

8. Bayvordi, A. 2006. Zinc in soils and crop nutrition. PhD thesis. Tabriz University. Tabriz, Iran.

9. Borras, L. and B. L. Gambin. 2010. Trait dissection of maize kernel weight: Towards integrating hierarchical scales using a plant growth approach. Field Crops Research 118(1): 1-12.

10. Campelo, D. H., A. D. S. Teixeira, L. C. Moreira and C. F. D. Lacerda. 2019. Growth, production and water and nitrogen use efficiency of maize under water depths and nitrogen fertilization. Revista Brasileira de Engenharia Agricola e Ambiental 23(10): 747-753.

11. Costa, C., L. M. Dwyer, D. W. Stewart and D. L. Smith. 2002. Nitrogen effects on grain yield and yield components of leafy and nonleafy maize genotypes. Crop Science 42(5): 1556-1563.

12. Gardner, F. P., R. B. Pearce and R. L. Mitchell. 2017. Physiology of Crop Plants. Scientific Publishers, Jodhpur.

13. Hatch, M. D. and C. R. Slack. 1966. Photosynthesis by sugar-cane leaves. A new carboxylation relation and the pathway of sugar formation. Biochemical Journal 101(1): 103-111.

14. Karic, L., S. Vukasinovic and D. Znidarcic. 2005. Response of leek (Allium porrum L.) to different levels of nitrogen dose under agro-climate conditions of Bosnia and Herzegovina. Acta Agriculture Slovenica 85: $219-226$.

15. Khan, H. Z., S. Iqbal, A. Iqbal, N. Akbar and D. L. Jones. 2011. Response of maize (Zea mays L.) varieties to different levels of nitrogen. Crop and Environment 2(2): 15-19.

16. Maleki Narag, M., H. R. Baluchi, H. Faraji and A. R. Yadavi. 2013. Effect of nitrogen and phosphorus biochemical fertilizers on grain yield and qualitative traits of sweet corn. Iranian Journal of Agricultural Knowledge and Sustainable Production 23: 89-104. (In Farsi).

17. Maranville, J. W. and S. Madhavan. 2002. Physiological adaptation for nitrogen use efficiency in sorghum. Plant Soil 245: 25-34.

18. Mirzakhani, M. 2015. The relationship between multiple ships simultaneously with legumes and the application of chemical and biofertilizers with agricultural nitrogen yield and field efficiency. Iranian Agricultural Knowledge and Sustainable Production 25: 17-32. (In Farsi).

19. Nemati, A., M. Sedghi, R. S. Sharifi and M. N. Seiedi. 2009. Investigation of correlation between traits and path analysis of corn (Zea mays L.) grain yield at the climate of Ardabil region (Northwest Iran). Notulae Botanicae Horti Agrobotanici Cluj-Napoca 37(1): 194-198.

20. Rozati, N. S., A. Gholami and H. R. Asghari. 2011. Study of nitrogen split application levels and variety effects on yield and agronomical characteristics of corn. Iranian Electronic Journal of Crop Production 4(2): 1-16. (In Farsi).

21. Saberali, S. F., M. A. Baghestani and E. Zand. 2008. Influence of corn density and planting pattern on the growth of common lambsquarters (Chenopodium album L.). Weed Biology and Management 8(1): 54-63.

22. Sajedi, N. and A. Ardekani. 2008. Effect of different levels of nitrogen, iron and zinc on physiological indices and forage yield of maize (Zea mays L.) in Markazi province. Iranian Journal of Crop Research 6(1): 99-110. (In Farsi).

23. Shamme, K., C. V. Raghavaiah, T. Balemi and I. Hamza. 2016. Sorghum (Sorghum bicolor L.) Growth, productivity, nitrogen removal, N- Use Efficiencies and Economics in relation to genotypes and nitrogen nutrition in Kellem- Wollega zone of Ethiopia, East Africa. Advances in Crop Science and Technology 4(3): 1-8.

24. Sharma, P. K., V. K. Kalra and U. S. Tiwana. 2016. Effect of farm yard manure and nitrogen levels on growth, quality and fodder yield of summer maize (Zea mays L.). Agricultural Research Journal 53(3): 355-559.

25. Somashekar, K. S., B. G. Shekara, K. N. Kalyana Murthy and L. Harish. 2014. Yield, nitrogen uptake, available soil 
nutrients and economics of multicut fodder sorghum (Sorghum sudanense L.) to different seed rates and nitrogen levels. Forage Research 40(1): 23-27.

26. Srivastava, R. K., R. K. Panda, A. Chakraborty and D. Halder. 2018. Enhancing grain yield, biomass and nitrogen use efficiency of maize by varying sowing dates and nitrogen rate under rainfed and irrigated conditions. Field Crops Research 221: 339-349.

27. Tafteh, A. and A. R. Sepaskhah. 2012. Yield and nitrogen leaching in maize field under different nitrogen rates and partial root drying irrigation. International Journal Plant Production 6(1): 93-113.

28. Tajul, M. I., M. M. Alam, S. M. M. Hossain, K. Naher, M. Y. Rafii and M. A. Latif. 2013. Influence of plant population and nitrogen-fertilizer at various levels on growth and growth efficiency of maize. The Scientific World Journal 2013: 1-9.

29. Tarighoislami, M., R. Zarghami, M. Mashhadi, A. Bojar and M. Oveisi. 2012. The effect of drought stress and nitrogen fertilizer amounts on physiological indices of grain maize. Iranian Journal of Agriculture and Plant Breeding 8(1): 174-161. (In Farsi).

30. Islam, M. T., A. S. Islam and M. S. Uddin. 2019. Physiological growth Indices of maize (Zea mays L.) genotypes in Sylhet. BioRxiv online 518993.

31. Tollennar, M. and L. M. Dwyer. 1999. Physioloy of maize. PP. 169-204. In: Smith D. L. and C. Hamel (eds.), Crop Yield, Physiology and Processes. Springer-Verlag, Berlin.

32. Tsimba, R., G. O. Edmeades, J. P. Millner and P. D. Kemp. 2013. The effect of planting date on maize grain yields and yield components. Field Crops Research 150: 135-144.

33. Wang, Y., B. Janz, T. Engedal and A. Neergaard. 2017. Effect of irrigation regimes and nitrogen rates on water use efficiency and nitrogen uptake in maize. Agricultural Water Management 179: 271- 276.

34. Wellburn, A. R. 1994. The spectral determination of chlorophylls a and b, as well as total carotenoids, using various solvents with spectrophotometers of different resolution. Journal Plant Physiology 144(3): 307-313.

35. Xu, Z. Z., Z. W. Yu, D. Wang and Y. L. Zhang. 2005. Nitrogen accumulation and translocation for winter wheat under different irrigation regimes. Journal of Agronomy and Crop Science 191(6): 439-449.

36. Yazdani, M., M. A. Bahmanyar, H. Pirdashti and M. A. Esmaili. 2009. Effect of phosphate solubilization microorganisms (PSM) and plant growth promoting rhizobacteria (PGPR) on yield and yield components of corn (Zea mays L.). World Academy of Science, Engineering and Technology 49: 90-92.

37. Zhao, D., K. R. Reddy, V. G. Kakani, J. J. Read and G. A. Carter. 2003. Corn (Zea mays L.) growth, leaf pigment concentration, photosynthesis and leaf hyperspectral reflectance properties as affected by nitrogen supply. Plant and Soil 257: 205-218.

38. Zhu, S., J. M. Vivanco and D. K. Manter. 2016. Nitrogen fertilizer rate affects root exudation: the rhizosphere microbiome and nitrogen-use-efficiency of maize. Applied Soil Ecology 107: 324-333. 


\title{
Growth Characteristics and Yield Evalution of Dual Purpose Corn Hybrids in Two Levels of Urea Fertigation
}

\author{
Z. Eskandari ${ }^{1}$, A. Taab ${ }^{2}$, H. R. Eshghizadeh ${ }^{3}$ and M. Khorvash ${ }^{4}$
}

(Received: January 03-2021; Accepted: May 19-2021)

\begin{abstract}
To study the response of corn hybrids to nitrogen under different conditions two field experiments were conducted in a split plot based on a randomized complete block design with three replications in Lavark and Shervedan Research Farms of College of Agriculture, Isfahan University of Technology, Isfahan, Iran, in 2016. The nitrogen fertilizer management (including 150 and $200 \mathrm{~kg} \mathrm{ha}^{-1}$ in Lavark; and 200 and $250 \mathrm{~kg} \mathrm{ha}^{-1}$ in Shervedan) regions was assigned to main plots and 20 grain-silage corn hybrids were assigned to subplots. The results showed that increased nitrogen fertilizer improve the LAI and CGR in corn hybrids. At Shervedan region, plant height in Maxima corn hybrid significantly increased by increasing of nitrogen. Increased nitogen fertilizer, also increased the amount of photosynthetic pigments in Shervedan and chlorophyll a content in Lavark region. The highest biological and grain yield were, respectively, obtained in AGN591 (29800 $\left.\mathrm{kg} \mathrm{ha}^{-1}\right)$ and Maxima (13150 kg ha'-1) hybrids in Shervedan region and in AGN756 (27200 kg ha-1) and AGN735 (11692 kg ha-1)in Lavark region with increased application of nitrogen. Therefore, depending on the purpose of the production system (e.g. grain or silage) the results of this research can be used to select corn hybrid and proper amount of nitrogen fertilizer to obtain acceptable yields and also reduce the adverse environmental effects of improper application of nitrogen fertilizers.
\end{abstract}

Keywords: Crop Growth Rate, Net assimilation rate, Chlorophyll content, Nitrogen, Corn hybrid.

1, 2. Ph.D. Student and Assistant Professor, Respectively, Department of Agronomy and Plant Breeding, College of Agriculture, Ilam University, Ilam, Iran.

3, 4. Assistant Professor, Department of Agronomy and Plant Breeding and Professor, Department of Animal Sciences, College of Agriculture, Isfahan University of Technology, Isfahan, Iran.

*: Corresponding Author, Email: a.taab@ilam.ac.ir 